\title{
Antibacterial, Antifungal, and Cytotoxic Activity of Excoecaria agallocha Leaf Extract
}

\author{
Kuzhunellil Raghavanpillai Sabu' \\ Sujith Sugathan ${ }^{2}$ \\ Akbar Idhayadhulla ${ }^{3}{ }^{3}$ \\ Melat Woldemariam (iD) ${ }^{4}$ \\ Addis Aklilu (iD ${ }^{4}$ \\ Gelila Biresaw (iD) 4 \\ Behailu Tsegaye (D) ${ }^{5}$ \\ Aseer Manilal (iD) ${ }^{4}$ \\ 'Department of Chemistry, College of \\ Natural and Computational Sciences, \\ Arba Minch University, Arba Minch, \\ Ethiopia; ${ }^{2}$ Department of Botany, Sree \\ Narayana College, Kollam, Kerala, India; \\ ${ }^{3}$ Research Department of Chemistry, \\ Nehru Memorial College (affiliated with \\ Bharathidasan University), Tiruchirappalli, \\ Tamil Nadu, India; ${ }^{4}$ Department of \\ Medical Laboratory Sciences, College of \\ Medicine and Health Sciences, Arba \\ Minch University, Arba Minch, Ethiopia; \\ ${ }^{5}$ Department of Biomedical Sciences, \\ College of Medicine and Health Science, \\ School of Medicine, Arba Minch \\ University, Arba Minch, Ethiopia
}

Correspondence: Aseer Manilal Email aseermanilal@gmail.com
Background: Mangroves contain several bioactive compounds, some of which have been used for centuries as remedies for several ailments.

Methods: Foliar parts of Excoecaria agallocha were extracted in organic solvents and in water using a Soxhlet apparatus and evaluated for antimicrobial activity against nine typeculture pathogens, six clinical isolates, and two fungal pathogens with agar well diffusion assays. Minimum inhibitory concentration (MIC) and minimum bactericidal concentration (MBC) were determined by broth dilution and extracts further subjected to brine-shrimp cytotoxic assays using Artemia salina. Chemical constituents were analyzed with thin-layer chromatography (TLC), gas chromatography-mass spectroscopy (GC-MS), and Fouriertransform infrared spectroscopy (FT-IR).

Results and Discussion: Ethyl acetate extract displayed the broadest antimicrobial activity. Isolates of Staphylococcus aureus were found to be the most susceptible among the clinical and type-culture groups corresponding to inhibition zones: $17.3 \pm 1.1$ and $23.5 \pm 1.3 \mathrm{~mm}$ in diameter, respectively. Anticandidal activity was found to be lower against Candida albicans and $C$. tropicalis $(10.3 \pm 0.6$ and $11.9 \pm 0.85 \mathrm{~mm}$ diameter). Also, this extract was found to be bactericidal for $S$. aureus and Micrococcus luteus (MBC:MIC $\leq 2$ ). ${ }_{\mathrm{C}}$ cytotoxic activity $\mathrm{LD}_{50}$ was $521 \mu \mathrm{g} / \mathrm{mL}$. On GC-MS, squalene [ $(6 E, 10 E, 4 E, 18 E)-2,6,10,15,19,23$-hexamethyltetracosa-2,6,10,14,18,22-hexaene] was the major compound. Bioassay-guided (antibacterial) TLC revealed the presence of one major active fraction, F2, with an $R_{f}$ value of 1.21. FT-IR analysis of this fraction also implied that it was squalene, which might have a functional role in the mechanism of chemical defense.

Keywords: mangrove, plant extract, antimicrobial, cytotoxicity, bioactive compounds, squalene

\section{Introduction}

A huge number of synthetic molecules are currently in use as antibacterial, antiviral, antiprotozoal, and antihelminthic agents. Nevertheless, as per the World Health Organization (WHO), the basic health needs of approximately $80 \%$ of the population in developing countries, even today, are met by traditional medicines. ${ }^{1} \mathrm{~A}$ variety of plant species, both terrestrial and aquatic, provide a large number of bioactive compounds, with negligible side effects, catering to the medicinal needs of mankind, and are also safer than their synthetic counterparts. ${ }^{2,3}$ In this context, terrestrial plants contribute a major share. Several drug formulations on the market consist of natural therapeutic agents of plant origin. There are numerous examples, including drugs for treating malaria (artemotile obtained from Artemisia annua), treating Alzheimer's disease (reminyl, isolated from Galanthus woronowii), and 
managing cancer (paclitaxel and its analogues, derived from Taxus brevifolia) and liver disorders (silymarin from Silybum marianum). ${ }^{2}$

Mangroves are a unique ecological niche that provide safe haven for numerous forms of estuarine and coastal life, can survive very harsh environmental conditions, and extend protection to their habitat by preventing seawater intrusion and functioning as natural nutrient filters. ${ }^{4}$ They can effectively participate in elemental biogeochemical cycling, including that of carbon. ${ }^{4}$ Several bioactive compounds can be isolated from mangroves. Excoecaria agallocha (Euphorbiaceae), which is also known as "blind-your-eye mangrove," is abundantly distributed in the wetlands of temperate and tropical regions of Asia, Africa, and northwest Australia. ${ }^{4}$ A literature survey showed that the mangrove has been used to treat toothache, swelling, sores, stings from marine creatures, and ulcers, and also as a purgative. ${ }^{5}$ It was also been used for the treatment of leprosy in earlier days. ${ }^{6}$

A recent review described a complete account on $E$. agallocha, including its ethnobotany, phytochemistry, and pharmacological aspects. ${ }^{4}$ Most of the available literature describes that this mangrove is a rich source of secondary metabolites with diverse bioactivity and an important candidate in the control of dreadful infectious diseases. ${ }^{5}$ The phytochemistry of the leaf extract of this plant contains mainly diterpenoids, triterpenoids, and flavonoids. ${ }^{7-9} \mathrm{~A}$ phorbol ester obtained from its leaves has been found to be a potent inhibitor of HIV1 replication, ${ }^{10}$ whereas polyphenols from the leaves showed inhibitory effects against hepatitis $\mathrm{C}$ virus ${ }^{11}$ and also anticancer activity (Hedgehog/ GLI signaling inhibitors). ${ }^{9}$ E. agalloch $a$ is a typical mangrove species widely distributed throughout the coastal area of Kerala, a southwestern state of India. The present study aimed to characterize the major phytochemical constituents and evaluate the antimicrobial and cytotoxic activity of the leaf extract of this plant from Kerala.

\section{Methods}

\section{Collection of E. agallocha Leaves and Extraction}

Tender foliage of E. agallocha (voucher specimen AEA-8, 2020) was collected from mature trees dotting the mangrove wetland of Ayiramthengu, Kollam district $\left(09^{\circ} 12^{\prime} \mathrm{N}\right.$ and $76^{\circ} 47^{\prime}$ E), Kerala state, India and identified taxonomically with the aid of an eminent mangrove taxonomist. Prior to extraction, the leaves were washed with water and cleaned to remove salts and other associated debris, chopped into small pieces, and dried under shade (to prevent photolysis and thermal degradation). The completely dried plant material was powdered in a coffee grinder and extracted using organic solvents of increasing polarity separately, such as chloroform (trichloromethane [TCM]), dichloromethane (DCM), ethyl acetate (EtOAc), and methanol $(\mathrm{MeOH})$, as well as water. ${ }^{12}$ All solvents used were of analytical grade and supplied by Merck India. In a typical batch, $100 \mathrm{~g}$ powdered material was extracted with $1 \mathrm{~L}$ of solvent in a Soxhlet apparatus for 5 hours, filtered using Whatman number one filter paper, concentrated in a rotary vacuum evaporator at $40^{\circ} \mathrm{C}$ (Yamato), then stored in a freezer at $-20^{\circ} \mathrm{C}$ for further studies.

\section{Test Microorganisms}

The antimicrobial activity of concentrated extracts were assessed using nine type-culture pathogens, consisting of both Gram-positive and Gram-negative strains (Table 1). Microbial Type Culture Collection (MTCC) strains were obtained from the Institute of Microbial Technology, Chandigarh, India. Clinical bacterial isolates (six species) and yeast cells (two species) were procured from different clinical laboratories. Fresh overnight bacterial cultures were prepared by transferring a loop full of inocula from stock cultures to test tubes containing nutrient broth sterilized at $121^{\circ} \mathrm{C}$ for 20 minutes. All bacterial strains were maintained on nutrient agar slants (HiMedia) at $37^{\circ} \mathrm{C} \pm 0.1^{\circ} \mathrm{C}$. Sabouraud Dextrose agar slant (HiMedia) was used for the routine propagation of Candida spp.

\section{Antimicrobial Assays}

Aliquots $(5 \mathrm{mg} / \mathrm{mL})$ of crude mangrove extracts in solvents were prepared and tested to find their antibacterial activity against pathogens, as per the agar well diffusion assay described previously. ${ }^{12}$ Sterile Mueller-Hinton agar was dispensed into petri plates. For antimicrobial assays, inocula were prepared from overnight cultures by the direct colony method. Distinct colonies were lifted directly from the plates with a sterile wire loop and suspended in $0.85 \%$ saline. Turbidity of the suspensions to be inoculated was adjusted in line with the 0.5 McFarland standard. Afterward, test organisms were uniformly swabbed over the Mueller-Hinton agar (HiMedia, India) surface. A $5 \mathrm{~mm}$-diameter well was made on the seeded surface using a sterile cork borer, and $100 \mu \mathrm{L}$ crude extract of a known concentration (5 $\mathrm{mg} / \mathrm{mL}$ ) was added. The solvent used for each extraction 
Table I Panel of pathogens used for antimicrobial assays

\begin{tabular}{|c|c|}
\hline \multirow[t]{9}{*}{ MTCC } & Staphylococcus aureus (MTCC 96); SA \\
\hline & Streptococcus mutans (MTCC 890); SM \\
\hline & Micrococcus luteus (MTCCI06); ML \\
\hline & Bacillus cereus (MTCC I306); BC \\
\hline & Aeromonas hydrophila (MTCC 646); $\mathrm{AH}$ \\
\hline & Klebsiella pneumoniae (MTCC I09); KP \\
\hline & Shigella flexneri (MTCC I457); SF \\
\hline & Escherichia coli (MTCC 739); EC \\
\hline & Pseudomonas aeruginosa (MTCC 2453); PA \\
\hline \multirow[t]{6}{*}{ Clinical isolates } & S. aureus \\
\hline & Pseudomonas spp.; PS \\
\hline & Proteus vulgaris; PV \\
\hline & E. coli \\
\hline & Citrobacter freundii; CF \\
\hline & Klebsiella spp.; KS \\
\hline \multirow[t]{2}{*}{ Yeast } & Candida albicans; CA \\
\hline & Candida tropicalis; CT \\
\hline
\end{tabular}

Abbreviation: MTCC, microbial type culture collection.

was taken as the negative control. Petri plates were then incubated for 24 hours at $37^{\circ} \mathrm{C}$ and inhibitory activity measured by calculating the diameter of the inhibition zone around the wells. Zones $\geq 8 \mathrm{~mm}$ were considered active. The assays were conducted in triplicate to validate the findings statistically $(P \leq 0.05)$. Anticandidal assays were performed according to the methodology described by Manilal et al. ${ }^{13}$ Cell suspensions containing approximately $10^{6} \mathrm{CFU} / \mathrm{mL}$ of yeast were prepared and inoculated on the surface of the agar plates, and wells were created that were filled with $100 \mu \mathrm{L}(5 \mathrm{mg} /$ $\mathrm{mL}$ ) leaf extract. To validate the inferences, wells with solvent used for extraction were considered negative controls. Assays were performed in triplicate in individual petri dishes. The diameter of the inhibition zone after 48 hours corresponds to the activity, and accordingly the zone of inhibition was calculated. Based on the diameter of zones of inhibition, antimicrobial activity was categorized as inactive $(<8 \mathrm{~mm})$, less active $(\geq 8$ to $<12 \mathrm{~mm}$ ), moderately active ( $\geq 12$ to $<20 \mathrm{~mm}$ ), and highly active ( $\geq 20 \mathrm{~mm})$.

\section{Determination of Minimum Inhibitory Concentration (MIC) and Minimum Bactericidal Concentration (MBC)}

Broth dilution was used for finding the MIC and MBC against the most susceptible group of type-culture isolates. ${ }^{14}$ The dosing range of EtOAc extracts of E. agallocha corresponded to a factor of 2 (antilog 0.3), the former related to the lowest concentration of leaf extract that prevents visible growth (indicated by the absence of turbidity) compared to the control. To measure the $\mathrm{MBC}$, MIC cultures were seeded $(10 \mu \mathrm{L})$ on Mueller-Hinton agar and incubated for 24 hours at $37^{\circ} \mathrm{C}$. It is actually the concentration that corresponds to nil growth of colonies compared to the culture of the initial inoculum of the same pathogen. If the ratio of MBC:MIC is $\leq 2$, then the plant extract is considered bactericidal and otherwise bacteriostatic. $^{15}$

\section{Brine-Shrimp Cytotoxic Assays}

Cytotoxic activity of the crude EtOAc extract of E. agallocha leaves was tested against freshly hatched free-swimming nauplii of Artemia salina (Great Salt Lake Artemia). The assay system was prepared using $2 \mathrm{~mL}$ filtered seawater containing extract in cavity blocks (embryo cup), and 20 nauplii were transferred to experimental and positive- and negative-control wells. The positive control is pure EtOAc and the negative control filtered seawater. The concentration of the experimental system was determined based on exploratory experiments. Mortality was determined in comparison to mean number of larvae surviving in the test sample and control tubes, and $\mathrm{LD}_{50}$ was determined using a probit scale. ${ }^{16}$

\section{GC-MS Analysis of EtOAc Leaf Extract}

The crude EtOAc leaf extract with antimicrobial activity was subjected to gas chromatography-mass spectrometry (Shimadzu QP2010) in a system fitted with a capillary column $(30 \mathrm{~m} \times 0.25 \mathrm{~mm})$ featuring a wide-range flame ionization detector and helium (99.99\%) carrier gas at 1 $\mathrm{mL} /$ minute flow rate. The oven temperature was kept at $110^{\circ} \mathrm{C}$ for 2 minutes and programmed to $280^{\circ} \mathrm{C}$ at a heating rate of $5^{\circ} \mathrm{C}$ per minute and then kept constant at $280^{\circ} \mathrm{C}$ for 10 minutes. Split ratio was $1: 20$ and the injection volume was $2 \mu \mathrm{L}$. The injection port and detector temperatures were maintained at $250^{\circ} \mathrm{C}$ and the electron ionization mode selected was $70 \mathrm{eV}$. The mass range analysed 
was $m / z$ 45-450 AMU. Identification of peaks corresponding to individual components were carried out by comparison with references (standards) available in the National Institute of Standards and Technology (NIST) and Wiley's libraries.

\section{Thin-Layer Chromatography (TLC) of EtOAc Extract}

The active EtOAc extract was fractionated using TLC. One gram of silica gel (mesh 60, Merck) was placed in a glass beaker $(50 \mathrm{~mL})$ and distilled water was slowly added and stirred with a glass rod until a thick but homogeneous fluid slurry was formed. Several clean slides $(3 \times 1$ in) were dipped into the slurry, withdrawn slowly, and held in vertical position for a couple of minutes in dry air. Using a micropipette, the leaf extract was loaded on one side of the coated slide, about $0.5 \mathrm{~cm}$ above the bottom end (preventing the larger drop from flowing down), subsequently allowing for air-drying for 10 minutes, which was then ready for developing. The slides were placed in a beaker containing 1\% EtOAc in DCM solvent. The solvent was allowed to run through the silica-gel layer until its front reached $1 \mathrm{~cm}$ below the top end and was then allowed to evaporate. After the development of the chromatogram, the resolved spots were analyzed by spraying $50 \%$ sulfuric acid to detect lipophilic compounds and $R_{f}$ values were calculated. The same procedure was repeated to collect a sufficient quantity $(1 \mathrm{mg})$ of each fraction for bioassay by scraping out and dissolving in EtOAc. The residual antimicrobial activity of separated fractions were redetermined against the two most susceptible type-culture bacteria - one each from the Gram-positive (S. aureus) and Gram-negative (K. pneumoniae) — by means of agar well diffusion assay, as described earlier.

\section{FT-IR Analysis}

The functional groups of components of the active fraction - F2 (ie, the one that showed consistent antimicrobial activity) - were analyzed and identified by recording the spectra between 4000-400 $\mathrm{cm}^{-1}$ (FT-IR spectrometer, Thermo FisherScientific).

\section{Data Analysis}

Data are presented as means \pm SD. SPSS 20 was used for analysis. $P \leq 0.05$ was considered statistically significant.

\section{Results \\ Yield of Extraction}

Yields of the vacuum-dried extracts varied according to the solvent used: $5.7 \%, 5.9 \%, 5.1 \%, 2.2 \%$, and $2.5 \%$ for EtOAc, MeOH, DCM, TCM, and water, respectively.

\section{Antibacterial and Antifungal Activity}

The results of screening revealed that of the five solvents used, EtOAc was the most appropriate, followed by $\mathrm{MeOH}$, for extraction of antimicrobial metabolites from E. agallocha leaves (Table 2). Antimicrobial activity was not found in the case of DCM and TCM or water extracts. Regarding type-culture isolates, Gram-positive bacteria were found to be more susceptible to the leaf extract, showing zones of inhibition of 23.5 $\pm 1.3-11.5 \pm 0.9 \mathrm{~mm}$. The highest activity was against $S$. aureus (23.5 $\pm 1.3 \mathrm{~mm}$ ), whereas the lowest was against Streptococcus mutans $(11.5 \pm 0.9 \mathrm{~mm})$. Moderate values against Gramnegative bacteria werte found for Klebsiella pneumoniae

Table 2 Antibacterial Activity of E. agallocha Leaf Extract Against Type-Culture Bacterial Pathogens

\begin{tabular}{|c|c|c|c|c|c|c|c|c|c|}
\hline Solvent used & SA & SM & ML & BC & KP & SF & EC & PA & $\mathbf{A H}$ \\
\hline & \multicolumn{7}{|c|}{ Zones of inhibition $(\mathrm{mm})$} & & \\
\hline EtOAc & $23.5 \pm 1.3$ & $11.5 \pm 0.9$ & $15.3 \pm 0.7$ & $13.2 \pm 1.2$ & $17.7 \pm 1.8$ & $12.4 \pm 1.2$ & $13.1 \pm 0.5$ & $14.5 \pm 1.3$ & $13.2 \pm 0.5$ \\
\hline $\mathrm{MeOH}$ & $17.3 \pm .5$ & $7 \pm 1.1$ & $10.5 \pm 0.9$ & $9 \pm 0.8$ & $\mid \mathrm{I} .4 \pm 1.4$ & $8 \pm 0.7$ & $10 \pm 1.3$ & $11.4 \pm 0.7$ & $8.2 \pm 1.1$ \\
\hline DCM & - & - & - & - & - & - & - & - & - \\
\hline TCM & - & - & - & - & - & - & - & - & - \\
\hline Water & - & - & - & - & - & - & - & - & - \\
\hline
\end{tabular}

Notes: Means $\pm S D ;-=$ no activity; zone of inhibition $\geq 8 \mathrm{~mm}$ considered active.

Abbreviations: SA, Staphylococcus aureus; SM, Streptococcus mutans; ML, Micrococcus luteus; BC, Bacillus cereus; KP, Klebsiella pneumoniae; SF, Shigella flexneri; EC, Escherichia coli; PS, Pseudomonas aeruginosa; AH, Aeromonas hydrophila. 
$(17.7 \pm 1.8 \mathrm{~mm})$ and Shigella flexneri $(12.4 \pm 1.2 \mathrm{~mm})$. Of the six clinical bacterial pathogens studied, a moderate zone of inhibition, $17.3 \pm 1.1 \mathrm{~mm}$ was found only in the case of $S$. aureus; while the lowest value was for the Gram-negative pathogen Proteus vulgaris $(9.8 \pm 1.4 \mathrm{~mm})$ Anticandidal activity of the crude EtOAc extract against C. albicans and C. tropicalis was lower: $11.9 \pm 0.85 \mathrm{~mm}$ and $10.3 \pm 0.6 \mathrm{~mm}$, respectively (Table 3 ).

The $\mathrm{MeOH}$ extract showed moderate activity against the type-culture isolate $S$. aureus, which produced an inhibitory zone of $17.3 \pm 0.5 \mathrm{~mm}$, followed by a couple of Gram negative isolates, such as K. pneumoniae (11.4 $\pm 1.4 \mathrm{~mm})$ and $P$. aeruginosa $(11.4 \pm 0.7 \mathrm{~mm})$, with more or less equal values of zones of inhibition falling close to the borderline between the less active and moderately active groups. Among the clinical isolates, again $S$. aureus was the pathogen most susceptible to the $\mathrm{MeOH}$ extract, exhibiting a moderate zone of inhibition $(13 \pm 0.9 \mathrm{~mm})$ whereas the extract was almost inactive against $C$. albicans $(7.8 \pm 0.32 \mathrm{~mm})$ and C. tropicalis $(7.5 \pm 0.4 \mathrm{~mm})$.

\section{MIC and MBC}

MIC was determined by broth-dilution assay using the crude EtOAc leaf extract, and the values determined against Gram-positive bacteria were $1,024-8,192 \mu \mathrm{g} / \mathrm{mL}$, with corresponding MBC values of 2,048-16,384 $\mu \mathrm{g} / \mathrm{mL}$ (Table 4). The lowest MIC and MBC values were produced against the Gram-positive bacteria $S$. aureus $(1,024$ and $2,048 \mu \mathrm{g} / \mathrm{mL}$, respectively). In the case of Gramnegative bacteria, MIC values were $1,024-4,096 \mu \mathrm{g} / \mathrm{mL}$, with concomitant MBC values of 4,096-8,192 $\mu \mathrm{g} / \mathrm{mL}$. The lowest MIC and MBC, values ie, 1,024 and 4,096 $\mu \mathrm{g} / \mathrm{mL}$, respectively, were found for $K$. pneumoniae and the extract was found to be bactericidal for $S$. aureus and M. luteus (MBC:MIC $\leq 2$ ) and bacteriostatic in the remaining cases (MBC:MIC $\geq 4$ ).

\section{Brine-Shrimp Cytotoxicity}

The EtOAc extract showed remarkable activity in brine shrimp cytotoxicity assay (Table 5), and the mortality rate of the nauplii increased with concentration. The crude extract showed an $\mathrm{LD}_{50}$ value of $521 \mu \mathrm{g} / \mathrm{mL}$.

\section{GC-MS Analysis of Crude EtOAc Extract}

Constituents of the crude EtOAc leaf extract identified by GC-MS analysis are shown in Table 6. By comparing the mass spectra of the constituents with the NIST library, ten compounds were identified, and the mass spectrum of the major component (peak area corresponding to $27.92 \%$ ) is shown in Figure 1, which indicates a molecular weight of 410 and the fragmentation pattern corresponding to that of the molecule squalene $-\mathrm{C}_{30} \mathrm{H}_{50}[(6 E, 10 E, 4 E, 18 E)$ 2,6,10,15,19,23-hexamethyltetracosa-2,6,10,14,18,22hexaene].

\section{TLC of Crude Extract}

The EtOAc leaf extract was subjected to preparative TLC using $1 \%$ EtOAc in DCM as the running solvent, and yielded four fractions with diverse $R_{f}$ values, ie, F1 4.3, F2 1.21, F3 1.09, and F4 1.02. In the agar well diffusion assay, the fraction F2 showed a higher range of activity against both the tested microorganisms (S. aureus [25

Table 3 Antimicrobial Activity of E. agallocha Leaf Extracts Against Bacterial and Fungal Clinical Isolates

\begin{tabular}{|c|c|c|c|c|c|c|c|c|}
\hline \multirow{2}{*}{$\begin{array}{l}\text { Solvents and controls } \\
\text { used }\end{array}$} & SA & PS & PV & EC & KP & CF & CA & CT \\
\hline & \multicolumn{8}{|c|}{ Zones of inhibition $(\mathrm{mm})$} \\
\hline EtOAc & $17.3 \pm 1.1$ & $9.9 \pm 1.3$ & $9.8 \pm 1.4$ & $10.5 \pm 1.09$ & $10.5 \pm 1.09$ & $11.2 \pm 1.3$ & $11.9 \pm 0.85$ & $10.3 \pm 0.6$ \\
\hline $\mathrm{MeOH}$ & $13.5 \pm 0.9$ & $9.1 \pm 1.05$ & $7.8 \pm 0.4$ & $9.7 \pm 0.4$ & $9.2 \pm 1.9$ & $10 \pm 0.8$ & $7.8 \pm 0.32$ & $7.5 \pm 0.4$ \\
\hline DCM & - & - & - & - & - & - & - & - \\
\hline TCM & - & - & - & - & - & - & - & - \\
\hline Water & - & - & - & - & - & - & - & - \\
\hline Ciprofloxacin & 23.5 & 20 & 21.5 & 28 & 21 & 26 & NT & NT \\
\hline Nystatin & NT & NT & NT & NT & NT & NT & 24 & 26 \\
\hline
\end{tabular}

Notes: Means $\pm \mathrm{SD}$; -, no activity; zone of inhibition $\geq 8 \mathrm{~mm}$ considered active.

Abbreviations: NT, not tested; SA, Staphylococcus aureus; PS, Pseudomonas spp.; PV, Proteus vulgaris; EC, Escherichia coli; KP, Klebsiella pneumoniae; CF, Citrobacter freundii; CA, Candida albicans; CT, Candida tropicalis. 
Table 4 MIC and MBC of EtOAc Extracts of E. agallocha Against Type Culture Bacterial Pathogens

\begin{tabular}{|l|l|l|l|}
\hline Test organisms & MIC $(\mu \mathrm{g} / \mathrm{mL})$ & MBC $(\mu \mathrm{g} / \mathrm{mL})$ & MBC:MIC \\
\hline S. aureus & 1,024 & 2,048 & 2 \\
\hline S. mutans & 4,096 & 16,384 & 4 \\
\hline M. luteus & 1,024 & 2,048 & 2 \\
\hline B. cereus & 2,048 & 8,192 & 4 \\
\hline K. pneumoniae & 1,024 & 4,096 & 4 \\
\hline S. flexneri & 2,048 & 8,192 & 4 \\
\hline E. coli & 2,048 & 8,192 & 4 \\
\hline P. aeruginosa & 2,048 & 8,192 & 4 \\
\hline A. hydrophila & 2,048 & 8,192 & 4 \\
\hline
\end{tabular}

Table 5 Brine-shrimp Cytotoxicity

\begin{tabular}{|l|c|c|c|}
\hline \multirow{2}{*}{ Sample } & \multicolumn{3}{|c|}{ Mortality (\%) at different concentrations ( $\mathrm{\mu g} / \mathrm{mL})$} \\
\cline { 2 - 4 } & $\mathbf{2 0 0}$ & $\mathbf{4 0 0}$ & $\mathbf{6 0 0}$ \\
\hline EtOAc extract of $E$. agallocha & $17.3 \pm 6.5$ & $44.2 \pm 5.6$ & 100 \\
\hline
\end{tabular}

Note: Means \pm SD.

$\pm 1.7 \mathrm{~mm}]$ and $K$. pneumoniae [22 $\pm 1.5 \mathrm{~mm}])$. Activity of the remaining fractions was found to be fluctuating (inconsistent), so these were thus excluded from further studies and analysis. Results suggested that the antimicrobial activity of the extract could be mainly attributed to F2, and its FT-IR spectrum was recorded.

\section{FT-IR Analysis}

FT-IR spectra were obtained to find the functional groups of components present in the active fraction F2 through the preparative TLC route (Figure 2). Absorption peaks corresponded to wavenumbers, 3,060-3,079, 685-695, and 1,668-1,678 $\mathrm{cm}^{-1}$, representing vibrations of $=\mathrm{C}-\mathrm{H}$ stretching, $=\mathrm{C}-\mathrm{H}$ bending, and $\mathrm{C}=\mathrm{C}$ stretching, respectively (of squalene molecule). The $\mathrm{C}=\mathrm{C}$ stretching vibration at the aforementioned wave number is very typical of the squalene molecule (matching the total number of six $\mathrm{C}=\mathrm{C}$ bonds). Absorption peaks at wavenumbers 28252855 and $1,325-1,355 \mathrm{~cm}^{-1}$ correspond to $-\mathrm{C}-\mathrm{H}$ stretching and $-\mathrm{C}-\mathrm{H}$ bending respectively.

\section{Discussion}

Antimicrobial activity of E. agallocha leaf extracts was tested against nine type-culture bacterial pathogens, six clinical isolates, and two Candida spp. Of all the pathogens screened, type-culture bacteria were the most susceptible organisms, while clinical bacterial and fungal pathogens proved resistant to a certain extent. The crude EtOAc extract showed the highest and widest activity. It efficiently repressed the growth of all tested organisms, whereas the $\mathrm{MeOH}$ extract showed only moderate to lower activity, but was not apparent in the the extract obtained using less polar solvents and water. The superior activity exhibited by EtOAc may be related to the presence of soluble and active polar components. A literature survey indicated that the antimicrobial activity of EtOAc extracts of foliar parts of E. agallocha is scanty. At the same time, earlier research reported the remarkable antibacterial activity of EtOH leaf extract of E. agallocha against $S$. aureus $(24 \mathrm{~mm}) .{ }^{17}$ Antimicrobial properties of fatty-acid methyl esters found in E. agallocha against $S$. aureus (16 $\mathrm{mm})$ and $B$. subtilis $(16 \mathrm{~mm})$ have also been reported. ${ }^{18}$

Excoecaria agallocha collected from another part (Goa) of India had a maximum zone of inhibition of $16.7 \mathrm{~mm}$ against $P$. mirabilis and $P$. vulgaris, but only $13 \mathrm{~mm}$ against $S$. aureus and Streptococcus spp. ${ }^{19}$ Likewise, another study done in India reported on antibacterial activity for $\mathrm{MeOH}$ extracts of E. agallocha against $S$. aureus and $P$. aeruginosa. ${ }^{20}$ The antibacterial activity of EtOH extract of E. agallocha bark exhibited 


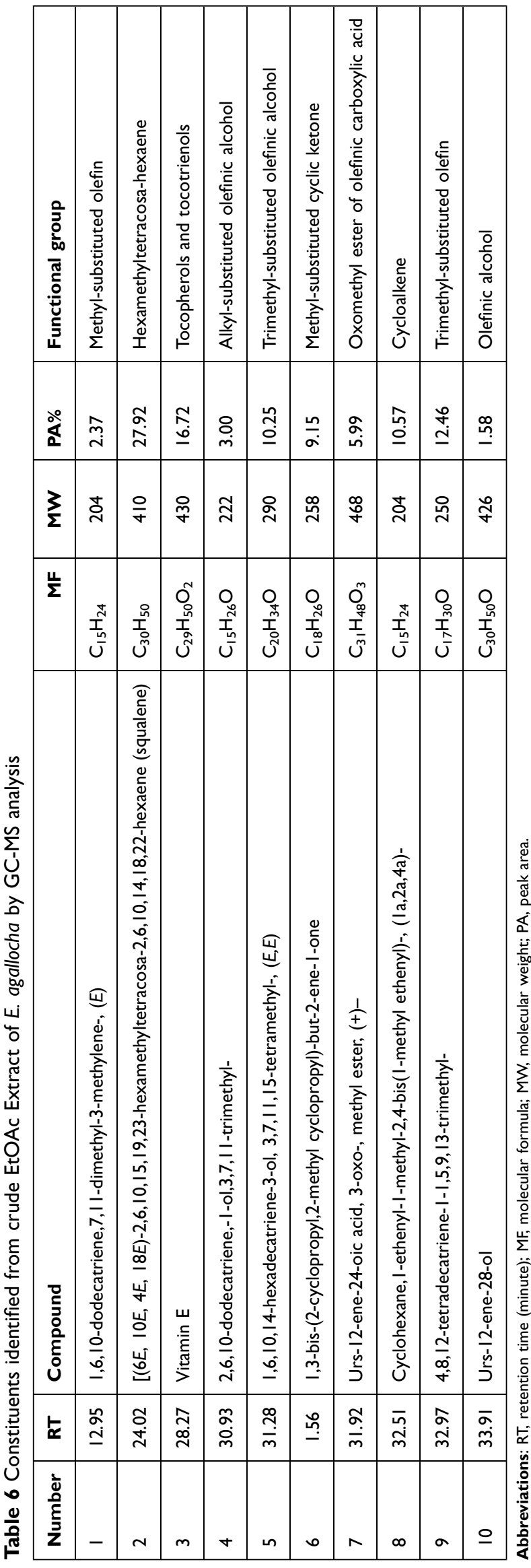

significant in vitro antibacterial activity against $S$. aureus, Shigella dysenteriae, S. sonnei, and Enterococci spp., with zones of inhibition of $11-15 \mathrm{~mm} .^{21}$

It is known that the antibiosis of plant extracts depends on several quintessential factors, such as season, geographical location, collection period, extraction methodology, purity of extract, and characteristics of test organisms. ${ }^{22,23}$ In the present study, Gram-positive bacteria were found to be highly susceptible compared to their Gram-negative counterparts. This trend has already been reported for other species of mangrove plants. ${ }^{22,24}$ In contrast, the Gram-positive cocci, S. mutans was found to be the most resistant bacteria in our study and further investigations are required to explain this contradiction. Of the diverse fungal pathogens, species of Candida cause fatal systemic infections that have been on the rise over the last decade. These are the most common opportunistic pathogen in AIDS patients. ${ }^{25} \mathrm{~A}$ higher degree of activity was displayed against the bacterial pathogens, while only a lower range of activity was produced against yeasts. Results of the antifungal activity against Candida spp. are by and large similar to the results of a previous work. ${ }^{13}$ This report is the first to describe possible anticandidal activity of $E$. agallocha from the southwest coast of India.

Widely varying MIC and MBC values were observed among the bacteria included in the current study. MIC values against Gram-positive bacteria were lower compared to their Gram-negative counterparts, except $S$. mutans. In the case of the former group, equally low MIC value $(1,024 \mu \mathrm{g} / \mathrm{mL})$ was recorded against both $S$. aureus and M. luteus, and MIC and MBC values obtained from our study were more or less similar to those reported in our previous publication. ${ }^{26}$ On the other hand, the currently observed MIC values were comparatively higher than those described in an earlier study, ${ }^{27}$ which reported values of 2-256 $\mu$ g against E. coli, B. subtilis, S. aureus, $P$. aeruginosa, and $K$. pneumoniae. These discrepancies observed in MIC and MBC values may be attributed to several factors, such as the nature of the crude extract, fluctuations in concentrations of metabolites, cytoplasmic permeability, and virulence factors associated with different types of bacteria. The exact mechanism of action of the antimicrobial activity of $E$. agallocha leaf extract against bacteria was not investigated in the present study. However, based on the results, activity against $S$. aureus and $M$. luteus was bactericidal (MBC:MIC $\leq 2$ ), whereas that against the rest was bacteriostatic (MBC:MIC $\geq 2$ ). 


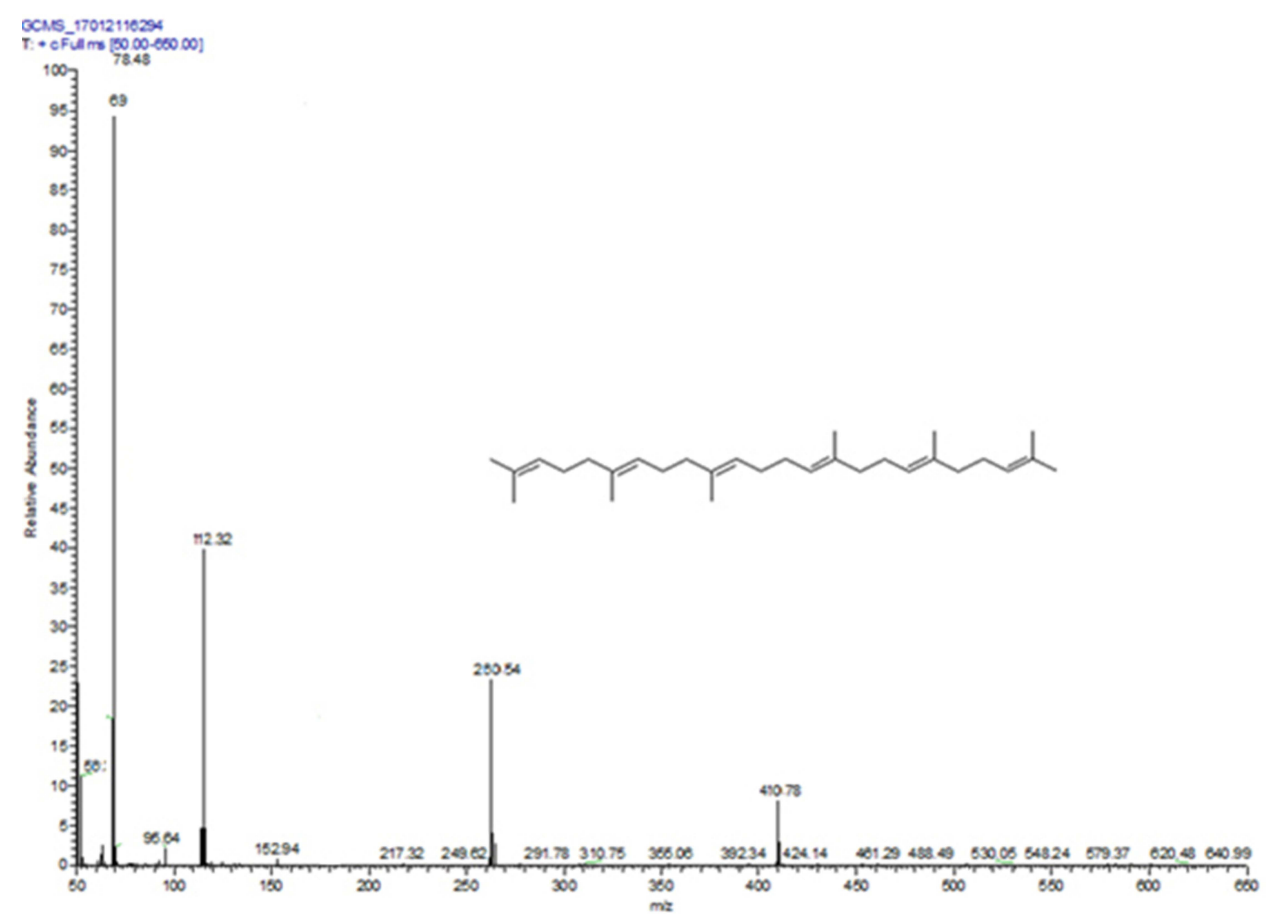

Figure I Mass spectrum of the compound number 2 (squalene), corresponding to the major peak in the GC (RT 24.02).

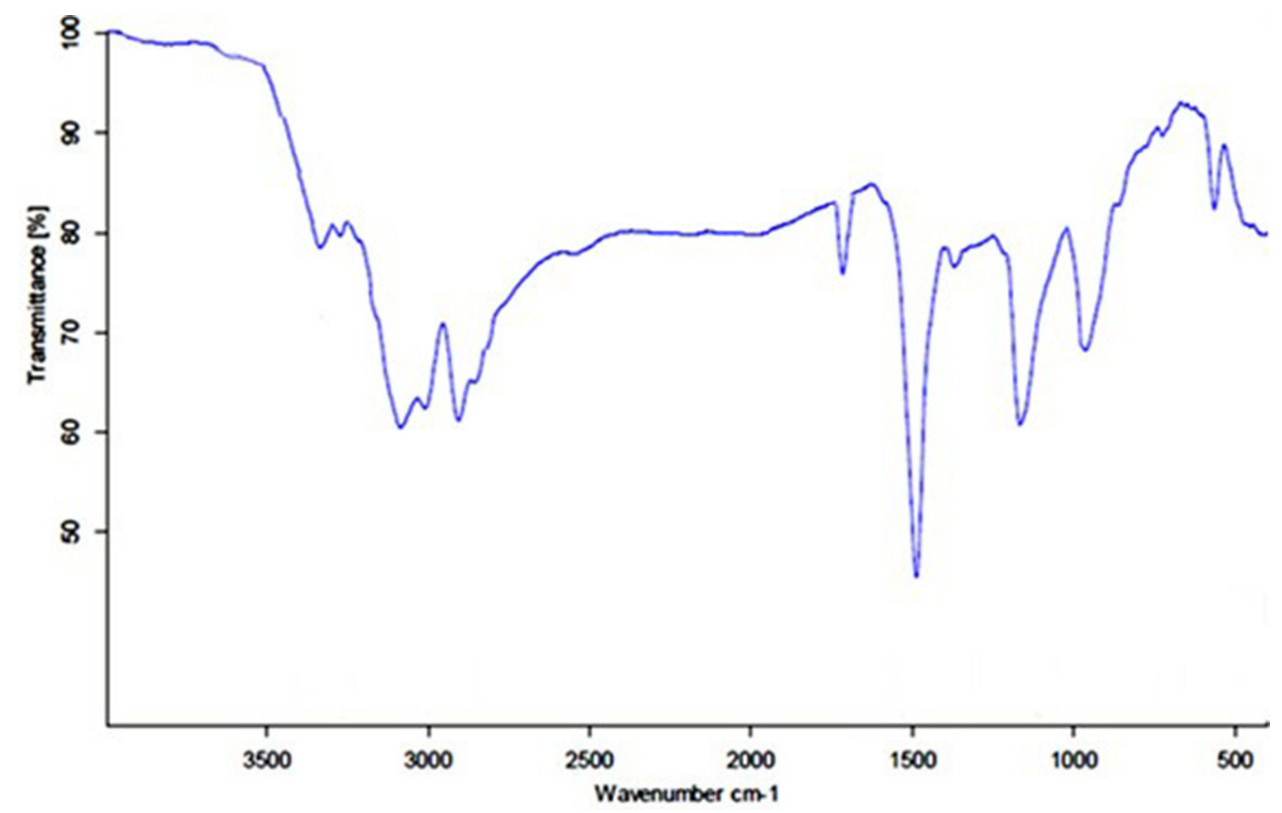

Figure 2 FT-IR spectrum of the major compound number 2 (squalene), obtained from the active fraction F2 of preparative TLC.

The overall results showed remarkable antibacterial potential for leaf extracts of E. agallocha.

The brine-shrimp assay is recognized as a reliable indicator of preliminary evaluation of toxicity and can be extrapolated to assess cell-line toxicity and antitumor activity. ${ }^{28}$ This assay is widely employed in the screening of several plant species for identification and isolation of useful components. It is envisaged that the cytotoxic activity exhibited by E. agallocha leaf extract is due to the presence of antitumor metabolites (mainly squalene). ${ }^{29-31}$ 
Cytotoxic activity of E. agallocha extract with varied $\mathrm{LD}_{50}$ against $A$. salina has already been reported. ${ }^{21}$ Discrepancies in $\mathrm{LD}_{50}$ observed by various authors could be related to differences in seasonality, geographical distribution of mangroves, and extraction methodology employed, including the types of solvent.

GC-MS analysis of EtOAc leaf extract revealed that there were ten compounds therein. The antimicrobial activities of individual constituents were not studied. The component with the highest peak area $(27.92 \%)$ was squalene $(2,6,10,15,19,23$-hexamethyltetracosa-2,6,10,14,18,22-

hexaene) according to the NIST database. The extract was further subjected to bioassay-guided fractionation using preparatory TLC followed by FT-IR spectroscopy, and the major compound again was found to be squalene as per the spectra, with several characteristic absorption peaks. ${ }^{32}$ Squalene is a linear triterpene found in plants and animals, including sea fish, and has diverse pharmacological, cosmetic, and nutritional potential. ${ }^{29} \mathrm{~A}$ scan of the literature indicated that squalene in E. agallocha has been reported widely, ${ }^{33,34}$ and also that antibacterial activity of leaf extracts of several species of mangroves containing squalene has already been reported. For instance, one study reported that squalene was the principal compound present in the active fraction of Rhizophora mucronata. ${ }^{35}$ In our previous study, it was found that squalene in Sonneratia alba was effective in decimating bacterial growth. ${ }^{22}$ It has been found to exist in other terrestrial flora too, eg, Polygonum chinense. ${ }^{36}$ Another study has shown that the antibacterial activity of Artocarpus leaf extract could be due to the presence of squalene. ${ }^{37}$ Earlier phytochemical studies on E. agallocha revealed the presence of diterpenoids ${ }^{8}$ and triterpenoids. ${ }^{7}$ Antimicrobial and cytotoxic activities of squalene isolated from different plants have been reviewed. ${ }^{38}$ The antimicrobial activity displayed by $E$. agallocha leaf extract could correspond to the presence of the major component, squalene, or could even be related to the synergistic activity of several components. However, this hypothesis needs to be explored further by a bioassayguided isolation of each individual component.

\section{Conclusion}

Leaf extracts of E. agallocha in organic solvents were evaluated for antimicrobial activity against nine type-culture pathogens, six clinical isolates, and two Candida spp. The extract obtained using the medium polar solvent EtOAc displayed maximum antimicrobial efficacy and significant cytotoxic activity. Overall, Gram-positive bacteria, particularly $S$. aureus, in both type-culture and clinical isolates were found to be more susceptible. GCMS of EtOAc extract revealed the presence of ten compounds. Results of TLC and FT-IR ultimately proved that the principal compound was squalene and correlated with bioactivity. This study covered the phytochemical and in vitro biological activity of E. agallocha with regard to the curbing of bacterial and fungal growth. Based on these findings, bioassay-guided fractionation and purification of extracts of E. agallocha leaves may provide useful antibiotic and cytotoxic leads.

\section{Ethics}

No ethics approval was required for this study, because it did not involve any human or animal subjects.

\section{Acknowledgment}

The authors are thankful to the Department of Science and Technology, Government of India for providing financial support (GC-MS and FT-IR instruments) to Nehru Memorial College, Puthanampatti, Tamil Nadu, India under the FIST program, New Delhi, India.

\section{Funding}

No financial support was received for this study.

\section{Disclosure}

The authors declare that they have no conflicts of interest.

\section{References}

1. Robinson M, Zhang X. The world medicines situation. Tradit Med. 2011;187:1-12.

2. Atanasov AG, Waltenberger B, Pferschy-Wenzig EM, et al. Discovery and resupply of pharmacologically active plant-derived natural products: a review. Biotechnol Adv. 2015;33(8):1582-1614. doi:10.1016/j. biotechadv.2015.08.001

3. Beutler JA. Natural products as a foundation for drug discovery. Curr Protoc Pharmacol. 2019;86(1):e67. doi:10.1002/cpph.67

4. Mondal S, Ghosh D, Ramakrishna K. A complete profile on blindyour-eye mangrove Excoecaria agallocha L. (Euphorbiaceae): ethnobotany, phytochemistry, and pharmacological aspects. Pharmacogn Rev. 2016;10(20):123-138. doi:10.4103/0973-7847.194049

5. Ghani A. Medicinal Plants of Bangladesh. 2nd ed. The Asiatic Society of Bangladesh; 2003:228-229.

6. Kirtikar KR, Basu BD. Indian Medicinal Plants. Vol. IIV. Allahabad, India: Lalit Mohan Basu Publishers; 1999.

7. Zou JH, Dai J, Chen X, Yuan JQ. Pentacyclic triterpenoids from leaves of Excoecaria agallocha. Chem Pharm Bull. 2006;54(6):920-921. doi:10.1248/cpb.54.920

8. Wang JD, Zhang W, Li ZY, Xiang WS, Guo YW, Krohn K. Elucidation of excogallochaols A-D, four unusual diterpenoids from the Chinese mangrove Excoecaria agallocha.. Phytochemistry. 2007;68(19):2426-2431. doi:10.1016/j.phytochem.2007.05.015 
9. Rifai Y, Arai MA, Sadhu SK, Ahmed F, Ishibashi M. New hedgehog/ GLI signalling inhibitors from Excoecaria agallocha. Bioorg Med Chem Lett. 2011;21:718-722. doi:10.1016/j.bmcl.2010.11.126

10. Erickson KL, Beutler JA, Cardellina IIJH, McMahon JB. A novel phorbol ester from Excoecaria agallocha L. J Nat Prod. 1995;58:769-772. doi:10.1021/np50119a020

11. Li Y, Yu S, Liu D, Proksch P, Lin W. Inhibitory effects of polyphenols toward HCV from the mangrove plant Excoecaria agallocha L. Bioorg Med Chem Lett. 2012;22:1099-1102. doi:10.1016/j. bmcl.2011.11.109

12. Manilal A, Idhayadhulla A. Potential in vitro antimicrobial efficacy of Holigarna arnottiana (Hook F). Asian Pac J Trop Biomed. 2014;4 (1):25-29. doi:10.1016/S2221-1691(14)60203-3

13. Manilal A, Tsalla T, Ameya G, et al. Evaluating the antibacterial and anti-Candidal potency of mangrove, Avicennia marina. Asian Pac J Trop Dis. 2016;6(2):136-140. doi:10.1016/S2222-1808(15)60999-9

14. Manilal A, Sabu KR, Shewangizaw M, et al. In vitro antibacterial activity of medicinal plants against biofilm-forming methicillin-resistant Staphylococcus aureus: efficacy of Moringa stenopetala and Rosmarinus officinalis extracts. Heliyon. 2020;6(1):e03303. doi:10.1016/j.heliyon.2020.e03303

15. Manilal A, Sabu KR, Woldemariam M, et al. Antibacterial activity of Rosmarinus officinalis against multidrug-resistant clinical isolates and meat-borne pathogens. Evid Based Complement Alternat Med. 2021;2021:6677420. doi:10.1155/2021/6677420

16. Wardlaw AC. Practical Statistics for Experimental Biologists. UK: John Wiley \& SonsLtd.; 1985.

17. Prakash M, Sivakumar T. A study on antibacterial activity of mangrove plant Excoecaria agallocha L. Int J Curr Microbiol Appl Sci. 2013;2:260-262.

18. Agoramoorthy G, Chandrasekaran M, Venkatesalu V, Hsu MJ. Antibacterial and antifungal activities of fatty acid methyl esters of the blind-your-eye mangrove from India. Braz $J$ Microbiol. 2007;38:739-742. doi:10.1590/S1517-83822007000400028

19. Sahoo G, Mulla NS, Ansari ZA, Mohandass C. Antibacterial activity of mangrove leaf extracts against human pathogens. Indian J Pharm Sci. 2012;74(4):348-351. doi:10.4103/0250-474X.107068

20. Patra J, Gouda S, Sahoo S, Thatoi H. Chromatography separation, H NMR analysis and bioautography screening of methanol extract of Excoecaria agallocha L. from Bhitarkanika, Orissa, India. Asian Pac J Trop Biomed. 2012;2:S50-S56. doi:10.1016/S2221-1691(12)60129-4

21. Subhan N, Alam MA, Ahmed F, Shahid IJ, Nahar L, Sarker SD. Bioactivity of Excoecaria agallocha. Braz J Pharmacogn. 2008;18:521-526. doi:10.1590/S0102-695X2008000400004

22. Manilal A, Merdekios B, Gezmu T, Idhayadhulla A. An in vitro antibacterial and anticandidal activity of Sonneratia alba (J. Smith). Thalassas. 2015;31:67-73.

23. Tiwari P, Kumar B, Kaur M, Kaur G, Kaur H. Phytochemical screening and extraction: a review. Int Pharm Sci. 2011;1(1):98-106.

24. Manilal A, Merdekios B, Idhayadhulla A, Muthukumar C, Melkie M. An in vitro antagonistic efficacy validation of Rhizophora mucronata. Asian Pac J Trop Dis. 2015;5(1):28-32. doi:10.1016/S2222-1808(14) 60622-8
25. Köhler JR, Casadevall A, Perfect J. The spectrum of fungi that infects humans. Cold Spring Harb Perspect Med. 2014;5(1):a019273. doi:10.1101/cshperspect.a019273

26. Vadlapudi V, Bobbarala V, Penumajji S, Naidu KC. Excoecaria agallocha L. Antimicrobial properties against important pathogenic microorganisms. Int J ChemTech Res. 2009;1:865-867.

27. Packialakshmi N, Kanimozhi P. Bioautography screening of a mangrove Excoecaria agallocha L. Int J Phytopharmacol. 2014;5:1-5.

28. Cyrus WG, Daniel GW, Nanyingi MO, Njonge FK, Mbaria JM. Antibacterial and cytotoxic activity of Kenyan medicinal plants. Mem Inst Oswaldo Cruz. 2008;103(7):650-652. doi:10.1590/s007402762008000700004

29. Lozano-Grande MA, Gorinstein S, Espitia-Rangel E, Dávila-Ortiz G, Martínez-Ayala AL. Plant sources, extraction methods, and uses of squalene. Int J Agron. 2018;2018:1-13. doi:10.1155/2018/1829160

30. Huang ZR, Lin YK, Fang JY. Biological and pharmacological activities of squalene and related compounds: potential uses in cosmetic dermatology. Molecules. 2009;14(1):540-554. doi:10.3390/ molecules 14010540

31. Yamawaki M, Azuma I, Saiki I, et al. Antitumor activity of squalenetreated cell-wall skeleton of Nocardia rubra in mice. Gan. 1978;69 (5):619-626.

32. Chun HJ, Weiss TL, Devarenne TP, Laane J. Vibrational spectra and DFT calculations of squalene. J Mol Struct. 2013;1032:203-206. doi:10.1016/j.molstruc.2012.10.008

33. Basyuni M, Putri LAP, Oku H. Phytomedicinal investigation from six mangrove tree species, North Sumatra, Indonesia (Invetigasi Fitomedisinal Enam Spesies Mangrove, Sumatera Utara, Indonesia). Ilmu Kelaut. 2013;18(3):157-164. doi:10.14710/ik.ijms.18.3.157-164

34. Desai N, Dethe U, Gaikwad D. Allelopathic effect of Excoecaria agallocha L. mangrove leaf leachate on germination and growth behavior of Eleusine coracana (Finger Millet). Am J Plant Physiol. 2017;12:38-44. doi:10.3923/ajpp.2017.38.44

35. Joel EL, Bhimba V. Isolation and characterization of secondary metabolites from the mangrove plant Rhizophora mucronata. Asian Pac J Trop Med. 2010;3:602-604. doi:10.1016/S1995-7645(10) 60146-0

36. Ezhilan BP, Neelamegam R. GC-MS analysis of phytocomponents in the ethanol extract of Polygonum chinense L. Pharmacognosy Res. 2012;4(1):11-14. doi:10.4103/0974-8490.91028

37. Biswas SM, Chakraborty N. Shedded Artocarpus leaves-good plant sources of natural squalene with potent antioxidant and antimicrobial activity-alternative to marine animals. J Nat Pharm. 2013;4(1):2127. doi:10.4103/2229-5119.110344

38. Patra JK, Thatoi HN. Metabolic diversity and bioactivity screening of mangrove plants: a review. Acta Physiol Plant. 2011;33(4):10511061. doi:10.1007/s11738-010-0667-7

\section{Publish your work in this journal}

The Journal of Experimental Pharmacology is an international, peerreviewed, open access journal publishing original research, reports, reviews and commentaries on all areas of laboratory and experimental pharmacology. The manuscript management system is completely online and includes a very quick and fair peer-review system. Visit http://www.dovepress.com/testimonials.php to read real quotes from published authors. 